\title{
Enzymatic breakage of dimethylsulfoniopropionate - a signature molecule for life at sea
}

\author{
Andrew W B Johnston, Robert T Green and Jonathan D Todd
}

School of Biological Sciences, University of East Anglia, Norwich Research Park, Norwich

NR4 7TJ, U.K.

Corresponding authors: Johnston, Andrew W B (a.johnston@uea.ac.uk) and Todd, Jonathan

D (jonathan.todd@uea.ac.uk)

\begin{abstract}
Largely using gene-based evidence, the last few years have seen real insights on the diverse ways in which different microbes break down dimethylsulfoniopropionate, an abundant antistress molecule that is made by marine algae, some corals and a few angiosperms. Here, we review more recent advances in which in vitro biochemical tools - including structural determinations - have shed new light on how the corresponding enzymes act on DMSP. These have revealed how enzymes in very different polypeptide families can act on this substrate, often by novel ways, and with broader implications that extend from enzymatic mechanisms to microbial ecology.
\end{abstract}

\section{Introduction}

The sulfur-containing zwitterion dimethylsulfoniopropionate (DMSP), is made in massive amounts ( $10^{9}$ tons annually, worldwide), with influences on diverse phenomena, from cloud formation to bird behavior [1]. Yet there is less general awareness of DMSP than these credentials deserve, most likely because it is a molecule of the seas and their margins. The marine organisms that make DMSP embrace single-celled plankton as diverse as dinoflagellates, diatoms and coccolithophores, as well as some red and green algal seaweeds, a few angiosperms [2], and, recently, the first DMSP-synthesizing animal, the coral Acropora was described [3]. DMSP may serve as an osmoprotectant, though other, anti-stress functions have been suggested (e.g. [4]); indeed, it may have different duties in the varied organisms that make it.

Although first identified in 1948 [5], we know little of how DMSP is made at a molecular genetic level, though some credible pathways were proposed (e.g. [6]). In contrast, there have been recent insights into how DMSP is catabolized, although awareness of this phenomenon, too, is not new. Cantoni and Anderson [7] showed in 1956 that the DMSPproducing macroalga Polysiphonia also broke it down to acrylate and the volatile dimethyl sulfide (DMS), as do other eukaryotic DMSP-producing organisms (see [8]). Furthermore, many marine bacteria can concentrate the DMSP that leaks from producer organisms, and then catabolise it. This process is not only a major driver of marine nutrition and global sulfur cycling, but the DMS product itself has diverse environmental effects. It is a chemoattractant 
for marine animals (birds, mammals and invertebrates), as indeed is DMSP itself $[9,10]$. And, at a very different level, DMS oxidation products cause atmospheric water molecules to coalesce, with possible effects on weather through cloud formation [11].

Furthermore, some abundant marine bacteria can catabolize DMSP in a very different way, in which the substrate is first demethylated in a pathway that allows some bacteria to use DMSP as a sulfur and/or carbon source [12-15].

This chapter encapsulates recent work on DMSP catabolism, emphasizing biochemical studies on the relevant enzymes, relating these to earlier genetic analyses (recently reviewed [12-15]).

\section{DMSP catabolism by eukaryotic phytoplankton}

Emiliania huxleyi is an abundant single-celled coccolithophore, long known not only to make DMSP, but to cleave it into DMS plus acrylate, possibly as a defense mechanism against zooplankton predation [16]. But, only very recently has the corresponding gene and its DMSP Iyase product been identified [8]. This nuclear gene, Alma1, encodes a tetrameric DMSP lyase that is sensitive to oxidative stress and is located in the cell's chloroplastic membrane [8]. Alma1 is in the aspartate/glutamate racemase super-family, which not only includes racemases sensu strictu, but has representatives with different functions, for example aryl-malonate decarboxylases and maleate cis-trans isomerases. These enzymes add or remove a proton from the carbon adjacent to a carboxylate, so Alma1 likely catalyzes the abstraction of a proton next to the DMSP carboxylate, releasing DMS plus acrylate (Figure 1).

An active DMSP lyase with low-level similarity ( $25 \%$ identical to Alma1) also occurs in the dinoflagellate Symbiodinium, a distantly related phytoplankton that interacts intimately with its Cnidarian host and is essential for coral productivity [17]. The functions of a range of polypeptides with similarly low sequence identity to Alma1 but which occur in diverse phytoplankton and even in bacteria are yet to be established. Interestingly, E. huxleyi itself has other poorly conserved Alma1 paralogues; those that were tested had very low DMSP lyase activity but the possibility that these were not expressed in soluble, fully functional form was not excluded [8]. One of these comprises two, tandemly arranged Alma1-type domains, superficially reminiscent of the architecture of the bacterial DMSP lyase DddD (below).

E. huxleyi strains differ in their baseline levels of DMS production and, nicely, this correlates with their amounts of Alma1 protein [8]. However, the intrinsic and/or extrinsic signals that affect expression of Alma1 are unknown. We did note, however, that published transcriptomic measurements indicated that E. huxleyi Alma1 and the Symbiodinium Alma1like gene were expressed at low levels in laboratory-grown cells. Expression was unaffected by temperature or salinity $[18,19]$, although transcription of $E$. huxleyi Alma1 was enhanced 3-fold in low-sulfate media $[18,19]$.

\section{Bacterial DMSP catabolism}


It was known for some time that DMSP could be catabolized by bacteria in two distinct ways - the "demethylation pathway" in which a methyl group is removed, yielding methylmercaptopropionate (MMPA), and a "Iysis" route in which DMS was produced, with some marine bacteria being able to accomplish both of these (see [16]).

To date, only one gene $(d m d A)$ that encodes a DMSP demethylase enzyme has been identified; in contrast, the lyases, encoded by different $d d d$ genes are of at least four different types (see $[12,13,20]$ ). We now consider recent biochemical analyses of these DmdA and Ddd gene products, summarized in Table 1.

\section{DmdA DMSP Demethylase}

The DMSP demethylase, DmdA, is found, mostly, in two clades of marine alphaProteobacteria, namely the Roseobacters and Pelagibacter ubique (SAR11), [21,22], both of which are very populous in the oceans, accounting for the widespread and abundant distribution of $d m d A$ genes in marine metagenomes. Our own inspection of the large ( $>4 \times 10^{7}$ non-redundant sequences) Tara Oceans data set [23] showed that $\sim 28 \%$ of the sampled cells contained $d m d A$, a similar value to that found in surveys of other metagenomes [22], notably that of the Global Ocean Survey (GOS) [24]. DmdA has significant (25\%) sequence identity to amino-methyltransferases of the glycine cleavage T-protein (GVT) family. In addition to their deamination activity, these enzymes transfer a methyl group to the acceptor molecule, usually tetrahydrofolate (THF) to yield 5, 10-methylene-THF. Atypically for members of this family, though, the methylated product of the DmdA-mediated demethylation of DMSP is 5-methyl-THF [25].

The recently obtained structure [26] of $P$. ubique DmdA shows that it is a dimer and although it adopts a fold that resembles other GVT family members, there are significant differences at both the THF- and nearby DMSP-binding sites. The structure revealed the proximity (3.3 $\AA$ ) of the N5 atom of THF and the methyl group on the DMSP's sulfonium atom, prompting a model that couples the methyl transfer (to THF) and the N5 proton to form a water molecule. Mechanistically, this more closely resembles that in the family of SAM-dependent methyltransferases, rather than that of other GVT enzymes. Thus, minor, precise differences near the active site of GVT family enzymes can affect the specificity and the enzymatic mechanism, even though the overall fold is little-changed.

\section{DMSP Lysis Pathway(s)}

The lysis pathway can be mediated by at least four classes of "Ddd" (ㅁMSP-dependent DMS) bacterial enzymes, representing different polypeptide families.

\section{- DddD Acetyl CoA Transferase}

The in vitro characterization of the DddD DMSP lyase [27] substantiates and extends earlier genetic and bioinformatic observations on this enzyme, identified first in the $\gamma$ Proteobacterium Marinomonas [28]. DddD is (so far) unique in that its C3 initial product is not acrylate, but 3-hydroxy-propionate (3HP), or a CoA-linked version thereof [28] (Figure 1). 
The DddD polypeptide has an unusual architecture, with similar, tandemly arranged domains. These both resemble CaiB, a Class III CoA-transferase involved in interconverting crotonobetaine and L-carnitine, the latter being structurally similar to DMSP [29]. DddD's catalytic mechanism likely involves an initial, acetyl-CoA-dependent covalent attachment of DMSP to the enzyme, possibly at an aspartate residue that is conserved at the C-terminal domain of all functional DddD enzymes [27]. Subsequent hydration of DMSP releases DMS plus $3 \mathrm{HP}$-CoA (and/or free, unmodified $3 \mathrm{HP}$ ). While resembling CaiB, both in sequence and in some of the proposed mechanisms, DddD has distinctive features. CaiB forms a homodimer of intertwining polypeptides [30]; although DddD may have a similar overall structure, this would comprise a single, larger polypeptide [27]. Also, CaiB CoA-transferase works in conjunction with a second enzyme, CaiD, which is responsible for hydrating carnitine CoA; in contrast, and unusually, DddD accomplishes both these reactions. Many bacteria containing DddD (mainly $\gamma$-Proteobacteria, e.g. Marinomonas) grow well on DMSP as sole carbon source [28,31]. Furthermore, $d d d D$ is often clustered with $d d d A$ and $d d d C$, which encode enzymes needed for subsequent, sequential catabolism of 3HP(-CoA) $[28,31]$, consistent with DddD's important role in DMSP-dependent nutrition. However, functionally ratified homologues of DddD also occur sporadically in other subphyla of Proteobacteria - e.g. Rhizobiales and Rhodobacterales (both $\alpha$-) and Burkholderiales $(\beta-)$ - pointing to repeated horizontal gene transfer (HGT) events [28].

This DddD-type architecture of two tandemly arranged CaiB domains is widespread in different bacterial taxa, albeit their sequences being less similar to those in DddD itself. The function(s) of these homologues is unknown. Further, it was noted [32] that E. huxleyi has a gene that would encode such a polypeptide. However, this does not appear to be a bona fide DMSP lyase, not least because this eukaryote makes acrylate, not 3HP, as its C3 DMSP cleavage product (see above).

- The "metallo-peptidase" DddP

The DddP DMSP lyase cleaves DMSP into DMS plus acrylate [33,34], and is widespread in bacteria of the Roseobacter and SAR116 clades, accounting for its relatively high abundance (4-26\% of sampled bacterial cells) in a number of marine metagenomes [22,35-37]. Functional DddP enzymes also exist in a few strains of other bacteria and, strikingly, in much more distantly related organisms, even including Ascomycete fungi, likely through interDomain HGT $[33,38]$. As predicted from its sequence [33] the recently described structures of DddP in two Roseobacters confirm it to be in the M24B sub-group of metalloproteases $[39,40]$, with the expected metalloproteinase-like 'pitta-bread' fold. It is dimeric [34], with the interface of the two monomers encompassing the active sites - one per monomer. Each site includes a binuclear metal centre, one occupied by Fe and the other by a choice of different metals. The two metal ions are co-ordinated to residues ( $3 \mathrm{x}$ aspartate, $2 \mathrm{x}$ glutamate and a histidine) that are conserved in all functional DddP enzymes (see Figure 4 in $[39,40])$. Other conserved residues (tryptophan and tyrosine) of DddP are proposed to bind to the $S^{+}$of DMSP via cation- $\pi$ interactions and orientate this substrate for electrostatic 
interaction with one Fe ligand at the carboxyl group, causing the Fe to move [40]. This ionshift would expose the remainder of the substrate to two residues (aspartate and glutamate) that would abstract a proton, leading to a beta-elimination, releasing DMS and acrylate. The model tallies with earlier site-directed substitutions of the predicted metal-binding amino acids; these completely abolished DMSP lyase activity [34].

\section{- Cupins}

The cupin motif comprises a metal-binding $\beta$-barrel and occurs in a vast number of polypeptides, with myriad functions [41]. No fewer than three different cupin-type DMSP lyases, DddL, DddQ and DddW have been identified to date - again, mostly in the marine Roseobacters [12]. These lyase enzymes share no extended amino acid similarity, except at this cupin motif, positioned towards their carboxyl termini. The recently presented structure [42] of DddQ and biochemical work on DddW [43], two cupin-type DMSP Iyases respectively from Ruegeria lacuscaerulensis and $R$. pomeroyi reveal that both are dimeric. Furthermore, both depend on a divalent metal cofactor, binding to three histidines and a glutamate residue within their cupin domains. These residues are conserved in the cupin DMSP lyases (Figure 2a), and modelling, based on the DddQ structure, shows that their predicted locations in DddL and DddW are very similar to those in DddQ. The crystallised DddQ protein contains a bound Zn whereas DddW is purified predominantly containing Fe. However, both these lyases can function with other divalent metal cofactors; viz $\mathrm{Mn}^{2+}$ and $\mathrm{Co}^{2+}$ for $\mathrm{DddQ}$ and $\mathrm{Mn}^{2+}$ and $\mathrm{Fe}^{2+}$ for DddW. Despite this apparent promiscuity, $\mathrm{Fe}^{2+}$ is the "preferred" ion for DddW, with a $\mathrm{K}_{d}$ of $\sim 5 \mathrm{nM}, \sim 200$-fold lower than other tested transition metals [43].

The proposed mechanism of cupin-containing DMSP lyases [42] for beta-elimination of a proton has novel features, in that initial binding of DMSP to the metal cofactor may cause movement of a nearby, conserved tyrosine ( $\mathrm{Y} 131$ for DddQ as shown in Figure 2b), bringing the oxygen atom of tyrosine closer to the alpha-carbon of DMSP, leading to the abstraction of a proton plus the release DMS and acrylate. It should be noted, though, that this model has been questioned by others [44].

\section{Closing discussion points}

The last few years have seen increasing amounts of biochemical flesh on earlier genetic and physiological bones of DMSP catabolism. And, again, the watchwords seem to be "novelty" and "variety". Even for those enzymes whose deduced amino acid sequences place them in known, and sometimes well-characterised, polypeptide families, several of them have distinctive features.

Thus:

- DddD is the first characterised enzyme with the tandem CaiB-CaiB CoA-transferase domain arrangement, maybe providing a template for other polypeptides with this architecture, in diverse organisms, but with, as yet, unknown function(s). 
- The proposed role of the mobile tyrosine residue in DddW, and by inference in other cupin-type lyases, is highly unusual - though see comments by others [44].

- Although DddP is in a family whose usual substrates are amino acids, and has an overall structure that resembles archetypal M24 proteases, DMSP is clearly not a peptide. However, subtle differences in the active site residues, and the ways that these may influence the interactions with metal cofactors may account for this difference in the natures of the substrates [40].

- Similarly, the DmdA DMSP demethylase, whose overall sequence and structure place it in one family (glycine cleavage T1), has a mode of action that more closely resembles that of the SAM-dependent methyltransferases.

And, yet another "Ddd" lyase, DddY, occurs in bacteria that favour microaerobic habitats and is (so far) unique in being periplasmic [45]. It does not resemble any polypeptide of known function, so elucidating its enzymatic details presents extra challenges, even though it was the first to have been purified [46] and even partially sequenced [47].

It will be of interest to establish if the varied types of enzymes that act on DMSP (and/or the organisms that harbour them) are adapted to function in particular marine environments. For example the local, perhaps transient, availability of particular metals may influence the effectiveness of the different metal-containing lyases.

Many enzymes that act on DMSP have strikingly (some might say "disturbingly") high $\mathrm{K}_{\mathrm{m}}$ values, in the millimolar values for DddP and DmdA and especially high for the cupins (Table 1). Also troubling are the low $K_{\text {cat }}$ values of some of the cupin lyases. Some authors (including ourselves [12]) asked if this hints that the "real" substrate for at least some of them may not be DMSP, but other, as yet unknown molecules [44]. Even though bacteria can concentrate DMSP to impressively high intracellular concentrations - as much as $70 \mathrm{mM} \mathrm{[25]} \mathrm{-} \mathrm{the}$ concerns raised by the values of these catalytic parameters still require unambiguous resolution. Of course, the question of what is the "correct", natural substrate for any given enzyme is not restricted to those that include DMSP as a substrate, and the consequences and origins catalytically promiscuous enzymes have been considered in some depth (e.g. [48]). Although some of these "DMSP lyases" may indeed turn out to be other than this term implies, the fact that their corresponding genes are seen in the metagenomes of bacteria that are from the seas and their margins and not, for example, in soils or in the human microbiome, strongly predicts that the "correct" substrate (if such there be) also has a marine distribution. For the moment at least, we go along with the inestimable Douglas Adams, who shrewdly noted that "If it looks like a duck and quacks like a duck, we have at least to consider the possibility that we have a small aquatic bird of the family Anatidae on our hands" [49].

In any event, although our understanding of how DMSP is catabolised has progressed significantly, on a number of fronts, there are still questions to be answered, ranging from enzyme mechanisms to microbial ecology. 


\section{Acknowledgements}

We are grateful to Changjiang Dong for helpful discussions on the structures of cupins. This work was funded by grants from the BBSRC and the NERC of the UK.

\section{References and Recommended Reading}

Papers of particular interest, published within the period of review, have been highlighted as:

- of special interest

$\bullet \bullet$ of outstanding interest

1. Kiene RP, Linn $\amalg$, Bruton JA: New and important roles for DMSP in marine microbial communities. Journal of Sea Research 2000, 43:209-224.

2. Borges AV, Champenois W: Seasonal and spatial variability of dimethylsulfoniopropionate (DMSP) in the Mediterranean seagrass Posidonia oceanica. Aquatic Botany 2015, 125:72-79.

3. Raina JB, Tapiolas DM, Foret S, Lutz A, Abrego D, Ceh J, Seneca FO, Clode PL, Bourne DG, Willis $\mathrm{BL}$, et al.: DMSP biosynthesis by an animal and its role in coral thermal stress response. Nature 2013, 502:677-680.

4. Sunda W, Kieber DJ, Kiene RP, Huntsman S: An antioxidant function for DMSP and DMS in marine algae. Nature 2002, 418:317-320.

5. Challenger F, Simpson MI: Studies on biological methylation; a precursor of the dimethyl sulphide evolved by Polysiphonia fastigiata; dimethyl-2-carboxyethylsulphonium hydroxide and its salts. J Chem Soc 1948, 3:1591-1597.

6. Gage DA, Rhodes D, Nolte KD, Hicks WA, Leustek T, Cooper AJ, Hanson AD: A new route for synthesis of dimethylsulphoniopropionate in marine algae. Nature 1997, 387:891-894. 7. Cantoni GÁ, Anderson DG: Enzymatic cleavage of dimethylpropiothetin by Polysiphonia lanosa. Journal of Biological Chemistry 1956, 222:171-177.

- 8. Alcolombri U, Ben-Dor S, Feldmesser E, Levin Y, Tawfik DS, Vardi A: MARINE SULFUR CYCLE. Identification of the algal dimethyl sulfide-releasing enzyme: $A$ missing link in the marine sulfur cycle. Science 2015, 348:1466-1469.

Some sixty years after the initial description of DMSP-dependent DMS production in a marine alga, this paper presents the first identification of the gene (Alma1) and corresponding product of a eukaryotic DMSP lyase.

9. Nevitt GA: The neuroecology of dimethyl sulfide: a global-climate regulator turned marine infochemical. Integr Comp Biol 2011, 51:819-825.

10. Seymour JR, Simo R, Ahmed T, Stocker R: Chemoattraction to dimethylsulfoniopropionate throughout the marine microbial food web. Science 2010, 329:342-345.

11. Welsh DT: Ecological significance of compatible solute accumulation by microorganisms: from single cells to global climate. FEMS Microbiol Rev 2000, 24:263-290. 12. Curson AR, Todd JD, Sullivan MJ, Johnston AW: Catabolism of dimethylsulphoniopropionate: microorganisms, enzymes and genes. Nat Rev Microbiol 2011, 9:849-859. 
13. Moran MA, Reisch CR, Kiene RP, Whitman WB: Genomic insights into bacterial DMSP transformations. Annual review of marine science 2012, 4:523-542.

14. Reisch CR, Moran MA, Whitman WB: Bacterial Catabolism of

Dimethylsulfoniopropionate (DMSP). Front Microbiol 2011, 2:172.

-15. Dickschat JS, Rabe P, Citron CA: The chemical biology of dimethylsulfoniopropionate. Org Biomol Chem 2015, 13:1954-1968.

This is a current and wide-ranging review of the synthesis and catabolism of DMSP.

16. Yoch DC: Dimethylsulfoniopropionate: its sources, role in the marine food web, and biological degradation to dimethylsulfide. Appl Environ Microbiol 2002, 68:5804-5815. 17. Yost DM, Mitchelmore CL: Dimethylsulfoniopropionate (DMSP) lyase activity in different strains of the symbiotic alga Symbiodinium microadriaticum. Mar Ecol Prog Ser 2009, 386:61-70.

18. Bochenek M, Etherington GJ, Koprivova A, Mugford ST, Bell TG, Malin G, Kopriva S: Transcriptome analysis of the sulfate deficiency response in the marine microalga Emiliania huxleyi. New Phytol 2013, 199:650-662.

19. Baumgarten S, Bayer T, Aranda M, Liew YJ, Carr A, Micklem G, Voolstra CR: Integrating microRNA and mRNA expression profiling in Symbiodinium microadriaticum, a dinoflagellate symbiont of reef-building corals. BMC Genomics 2013, 14:704.

20. Reisch CR, Crabb WM, Gifford SM, Teng Q, Stoudemayer MJ, Moran MA, Whitman WB: Metabolism of dimethylsulphoniopropionate by Ruegeria pomeroyi DSS-3. Mol Microbiol 2013, 89:774-791.

21. Howard EC, Henriksen JR, Buchan A, Reisch CR, Bürgmann H, Welsh R, Ye W, González JM, Mace K, Joye SB, et al.: Bacterial Taxa That Limit Sulfur Flux from the Ocean. Science 2006, 314:649-652.

22. Howard EC, Sun S, Biers EJ, Moran MA: Abundant and diverse bacteria involved in DMSP degradation in marine surface waters. Environ Microbiol 2008, 10:2397-2410.

23. Sunagawa S, Coelho LP, Chaffron S, Kultima JR, Labadie K, Salazar G, Djahanschiri B, Zeller G, Mende DR, Alberti A, et al.: Ocean plankton. Structure and function of the global ocean microbiome. Science 2015, 348:1261359.

24. Rusch DB, Halpern AL, Sutton G, Heidelberg KB, Williamson S, Yooseph S, Wu D, Eisen JA, Hoffman JM, Remington K, et al.: The Sorcerer II Global Ocean Sampling expedition: northwest Atlantic through eastern tropical Pacific. PLoS Biol 2007, 5:e77.

25. Reisch CR, Moran MA, Whitman WB: Dimethylsulfoniopropionate-dependent demethylase (DmdA) from Pelagibacter ubique and Silicibacter pomeroyi. J Bacteriol 2008, 190:8018-8024.

-26. Schuller DJ, Reisch CR, Moran MA, Whitman WB, Lanzilotta WN: Structures of dimethylsulfoniopropionate-dependent demethylase from the marine organism Pelagabacter ubique. Protein Sci 2012, 21:289-298.

This paper presents the structure and deduced mechanism of action of the DmdA DMSP demethylase of the SAR11 bacteria, the most abundant clade of bacteria anywhere.

-27. Alcolombri U, Laurino P, Lara-Astiaso P, Vardi A, Tawfik DS: DddD is a CoAtransferase/lyase producing dimethyl sulfide in the marine environment. Biochemistry 2014, 53:5473-5475. 
This study of the in vitro characteristics of the bacterial DddD DMSP lyase confirms earlier predictions that this unusual polypeptide has similarities but also some significant differences from the well-studied CaiB acetyl CoA transferase involved in carnitine metabolism in E. coli.

28. Todd JD, Rogers R, Li YG, Wexler M, Bond PL, Sun L, Curson ARJ, Malin G, Steinke M, Johnston AWB: Structural and regulatory genes required to make the gas dimethyl sulfide in bacteria. Science 2007, 315:666-669.

29. Elssner T, Engemann C, Baumgart K, Kleber HP: Involvement of coenzyme A esters and two new enzymes, an enoyl-CoA hydratase and a CoA-transferase, in the hydration of crotonobetaine to L-carnitine by Escherichia coli. Biochemistry 2001, 40:11140-11148. 30. Rangarajan ES, Li Y, lannuzzi P, Cygler M, Matte A: Crystal structure of Escherichia coli crotonobetainyl-CoA: carnitine CoA-transferase (CaiB) and its complexes with CoA and carnitinyl-CoA. Biochemistry 2005, 44:5728-5738.

31. Todd JD, Curson ARJ, Nikolaidou-Katsaraidou N, Brearley CA, Watmough NJ, Chan Y, Page PCB, Sun L, Johnston AWB: Molecular dissection of bacterial acrylate catabolismunexpected links with dimethylsulfoniopropionate catabolism and dimethyl sulfide production. Environ Microbiol 2010, 12:327-343.

32. Read BA, Kegel J, Klute MJ, Kuo A, Lefebvre SC, Maumus F, Mayer C, Miller J, Monier A, Salamov $A$, et al.: Pan genome of the phytoplankton Emiliania underpins its global distribution. Nature 2013, 499:209-213.

33. Todd JD, Curson ARJ, Dupont CL, Nicholson P, Johnston AWB: The dddP gene, encoding a novel enzyme that converts dimethylsulfoniopropionate into dimethyl sulfide, is widespread in ocean metagenomes and marine bacteria and also occurs in some Ascomycete fungi. Environ Microbiol 2009, 11:1376-1385.

34. Kirkwood M, Le Brun NE, Todd JD, Johnston AW: The dddP gene of Roseovarius nubinhibens encodes a novel lyase that cleaves dimethylsulfoniopropionate into acrylate plus dimethyl sulfide. Microbiology 2010, 156:1900-1906.

35. Carrión O, Curson ARJ, Kumaresan D, Fu Y, Lang AS, Mercadé E, Todd JD: A novel pathway producing dimethylsulphide in bacteria is widespread in soil environments. Nature communications 2015, 6:6597

36. Varaljay VA, Gifford SM, Wilson ST, Sharma S, Karl DM, Moran MA: Bacterial dimethylsulfoniopropionate degradation genes in the oligotrophic north pacific subtropical gyre. Appl Environ Microbiol 2012, 78:2775-2782.

37. Choi DH, Park KT, An SM, Lee K, Cho JC, Lee JH, Kim D, Jeon D, Noh JH: Pyrosequencing revealed SAR116 clade as dominant $d d d P$-containing bacteria in oligotrophic NW Pacific Ocean. PLoS One 2015, 10:e0116271.

38. Kirkwood M, Todd JD, Rypien KL, Johnston AW: The opportunistic coral pathogen Aspergillus sydowii contains $d d d P$ and makes dimethyl sulfide from dimethylsulfoniopropionate. ISME J 2010, 4:147-150.

-39. Hehemann JH, Law A, Redecke L, Boraston AB: The structure of RdDddP from Roseobacter denitrificans reveals that DMSP lyases in the DddP-family are metalloenzymes. PLoS One 2014, 9:e103128.

Together with the paper by Wang et al [40], this structural description of the DddP enzyme provides insights on the way that a member of a metallopeptidase family can act on DMSP. 
-40. Wang P, Chen XL, Li CY, Gao X, Zhu DY, Xie BB, Qin QL, Zhang XY, Su HN, Zhou BC, et al.: Structural and molecular basis for the novel catalytic mechanism and evolution of DddP, an abundant peptidase-like bacterial Dimethylsulfoniopropionate lyase: a new enzyme from an old fold. Mol Microbiol 2015, 98:289-301.

Together with the paper by Hehemann et al [39], this structural description of the DddP enzyme provides insights on the way that a member of a metallopeptidase family can act on DMSP.

41. Dunwell JM, Purvis A, Khuri S: Cupins: the most functionally diverse protein superfamily? Phytochemistry 2004, 65:7-17.

- 42. Li C-Y, Wei T-D, Zhang S-H, Chen X-L, Gao X, Wang P, Xie B-B, Su H-N, Qin Q-L, Zhang $X-Y$, et al.: Molecular insight into bacterial cleavage of oceanic dimethylsulfoniopropionate into dimethyl sulfide. Proc Natl Acad Sci U S A 2014, 111:1026-1031.

This paper reports the first structure of a bacterial DMSP lyase and presents a novel mechanism by which the DddQ DMSP lyase may effect the $\beta$-elimination of a proton to generate DMS plus acrylate.

-43. Brummett AE, Schnicker NJ, Crider A, Todd JD, Dey M: Biochemical, Kinetic, and Spectroscopic Characterization of Ruegeria pomeroyi DddW - A Mononuclear IronDependent DMSP Lyase. PLoS One 2015, 10:e0127288.

The DddW DMSP lyase is one of several cupin-type enzymes with this activity. This detailed in vitro analysis of this enzyme, together with the loss of function of site-directed mutants, confirms the importance of metal (iron)-binding and the role of the cupin motif.

44. Alcolombri U, Elias M, Vardi A, Tawfik DS: Ambiguous evidence for assigning DddQ as a dimethylsulfoniopropionate lyase and oceanic dimethylsulfide producer. Proc Natl Acad Sci U S A 2014, 111:E2078-2079.

45. Curson AR, Sullivan MJ, Todd JD, Johnston AW: DddY, a periplasmic

dimethylsulfoniopropionate lyase found in taxonomically diverse species of

Proteobacteria. ISME J 2011, 5:1191-1200.

46. de Souza MP, Yoch DC: Purification and characterization of dimethylsulfoniopropionate lyase from an alcaligenes-like dimethyl sulfide-producing marine isolate. Appl Environ Microbiol 1995, 61:21-26.

47. de Souza MP, Yoch DC: N-Terminal Amino Acid Sequences and Comparison of DMSP Lyases from Pseudomonas Doudoroffii and Alcagenes Strain M3A. In Biological and Environmental Chemistry of DMSP and Related Sulfonium Compounds. Edited by Kiene R, Visscher P, Keller M, Kirst G: Springer US; 1996:293-304.

48 Khersonsky O, Tawfik DS. Enzyme promiscuity: a mechanistic and evolutionary perspective. Ann Rev Biochem 2010, 79:471-505.

49 Adams D "Dirk Gently's Holistic Detective Agency" 1987 Published by William Heinemann. ISBN 0-671-69267-4.

50. Kearse M, Moir R, Wilson A, Stones-Havas S, Cheung M, Sturrock S, Buxton S, Cooper A, Markowitz S, Duran C, et al.: Geneious Basic: an integrated and extendable desktop software platform for the organization and analysis of sequence data. Bioinformatics 2012, 28:1647-1649. 
51. Biasini M, Bienert S, Waterhouse A, Arnold K, Studer G, Schmidt T, Kiefer F, Cassarino TG, Bertoni M, Bordoli L, et al.: SWISS-MODEL: modelling protein tertiary and quaternary structure using evolutionary information. Nucleic Acids Res 2014, 42:W252-258.

52. van der Maarel MJEC, van Bergeijk S, van Werkhoven AF, Laverman AM, Meijer WG, Stam WT, Hansen TA: Cleavage of dimethylsulfoniopropionate and reduction of acrylate by Desulfovibrio acrylicus sp. nov. Archives of Microbiology 1996, 166:109-115. 


\section{Figure Legends}

Figure 1. Products formed through the action of different enzymes that act on the substrate DMSP.

Dimethylsulfonioproprionate (DMSP) is converted to acrylate, dimethyl sulfide (DMS) and a proton via the DddL, Q, W, Y, P and Alma1 enzymes of the DMSP lyase pathway. The DddD enzyme of the CoA DMSP lysis pathway produces 3-hydroxypropionate (3HP)-CoA and DMS from DMSP, using acetyl-CoA as a CoA donor. The demethylation of DMSP by DmdA produces methylmercaptopropionate (3-MMPA) and methyl-tetrahydrofolate (THF). Bacterial enzymes are in pink background, eukaryotic in green, and DddP, found in both Domains, in yellow. The protein families of each enzyme are indicated.

Figure 2. Cupin motifs and metal binding residues of DddL, DddQ and DddW.

(A) Sequence alignment of cupin regions of selected DddL, DddQ and DddW proteins using sequences at $\mathrm{NCBI}$ and Geneious [50]. The two conserved cupin motifs 1 ( $G X_{5} \mathrm{HXHX}_{3,4} \mathrm{EX}_{6} \mathrm{G}$ ) and $2\left(\mathrm{GX}_{5} \mathrm{PXGX}_{2} \mathrm{HX}_{3} \mathrm{~N}\right)$ are boxed in red. The catalytically important, metal-binding histidine and glutamic acid residues are highlighted in green. The conserved Tyr residue shown to play a catalytic role in DddQ is marked in cyan. Other non-variant residues are colored yellow. The sequences are from: Q1 = DddQ, Ruegeria lacuscaerulensis (SL1157_0332); Q2= DddQ, Ruegeria pomeroyi DSS-3 (SPO1596); W1= DddW, Ruegeria pomeroyi DSS-3 (SPO0453); L1= DddL, Sulfitobacter sp. EE-36 (EE36_11918); L2= DddL, Rhodobacter sphaeroides 2.4.1 (RSP_1433). The numbers refer to the amino acid residues in $R$. lacuscaerulensis DddQ.

(B) The Zn(II)-bound structure (PDB 4LA2) [42] of Ruegeria lacuscaerulensis DddQ (magenta) was the template to model the active sites of DddL of Sulfitobacter sp. EE-36 (green) and DddW of Ruegeria pomeroyi DSS-3 (cyan), using SWISS-MODEL [51]). The catalytic residues $\mathrm{H} 123, \mathrm{H} 125, \mathrm{E} 129, \mathrm{Y} 131$ and $\mathrm{H} 163$ of $R$. lacuscaerulensis DddQ superimpose well in all three polypeptides. The figure was drawn using Pymol (PyMOL Molecular Graphics System, Version 1.7.4 Schrödinger, LLC). 
Table 1. Properties of DMSP lyases and DMSP demethylase DmdA.

\begin{tabular}{|c|c|c|c|c|c|c|c|}
\hline Enzyme & $\begin{array}{l}\text { DMSP Breakdown } \\
\text { Products }\end{array}$ & Polypeptide class & $\begin{array}{l}\text { Structure } \\
\text { known? }\end{array}$ & $\begin{array}{c}\text { Size of } \\
\text { polypeptide and } \\
\text { quaternary form } \\
\text { if known }\end{array}$ & $\begin{array}{c}\text { Co- } \\
\text { factors }\end{array}$ & $\begin{array}{l}\text { Enzyme } K_{m} \\
\text { for DMSP }\end{array}$ & $\begin{array}{l}\text { Taxonomic } \\
\text { distribution }\end{array}$ \\
\hline $\begin{array}{l}\text { ALMA1 } \\
\text { "lyase" }\end{array}$ & $\begin{array}{l}\text { acrylate }+ \text { dimethyl sulfide } \\
(\text { DMS) + proton }\end{array}$ & $\begin{array}{l}\text { Aspartate/glutamate } \\
\text { racemase super- } \\
\text { family }\end{array}$ & No & $\begin{array}{c}\text { Emiliania huxleyi } \\
\sim 350 \text { amino acids } \\
\text { MW } \sim 38 \mathrm{kDa} \\
\text { tetramer } \\
\text { Symbiodinium } \\
\sim 280 \text { amino acids } \\
\mathrm{Mr} \sim 31 \mathrm{kDa} \\
\end{array}$ & $\begin{array}{l}\text { None } \\
\text { known }\end{array}$ & $\begin{array}{c}\text { Emiliania } \\
\text { huxleyi } 9.0+/- \\
0.9 \mathrm{mM}[8]\end{array}$ & $\begin{array}{c}\text { Eukaryotic } \\
\text { Coccolithophore } \\
\text { Emiliania huxleyi and } \\
\text { Dinoflagellate } \\
\text { Symbiodinium }\end{array}$ \\
\hline DddY "lyase" & acrylate + DMS + proton & None known & No & $\begin{array}{l}\sim 400 \text { amino acids in } \\
\text { mature form after } \\
\text { removal of } \sim 21\end{array}$ & $\begin{array}{l}\text { None } \\
\text { known }\end{array}$ & $\begin{array}{l}\text { Alcaligenes } \\
\text { faecalis } \\
1.4 \mathrm{mM} \text { [47]; }\end{array}$ & $\begin{array}{l}\text { Periplasmic protein found } \\
\text { sporadically in } \\
\text { Proteobacteria that favor } \\
\text { microaerobic }\end{array}$ \\
\hline
\end{tabular}




\begin{tabular}{|c|c|c|c|c|c|c|c|}
\hline & & & & $\begin{array}{l}\text { amino acid } \mathrm{N}- \\
\text { terminal leader; } \\
\mathrm{MW} \sim 45 \mathrm{kDa}\end{array}$ & & $\begin{array}{l}\text { Desulfovibrio } \\
\text { acrylicus } 0.4 \\
\text { mM [52] }\end{array}$ & $\begin{array}{c}\text { environments, including } \\
\text { Alcaligenes, Arcobacter } \\
\text { (both } \beta) \text {, Desulfovibrio } \\
(\delta), \text { Shewanella }(\gamma)\end{array}$ \\
\hline $\begin{array}{l}\text { DddP } \\
\text { "lyase" }\end{array}$ & acrylate + DMS + proton & $\begin{array}{c}\mathrm{M} 24 \\
\text { metalloproteinase }\end{array}$ & $\begin{array}{c}\text { Yes, from } \\
\text { Roseobacter } \\
\text { denitrificans } \\
{[39,40] \text { and }} \\
\text { Ruegeria } \\
\text { lacuscaerulensis } \\
{[39,40]}\end{array}$ & $\begin{array}{l}\sim 390 \text { amino acids; } \\
\text { MW } \sim 44.5 \text { kDa dimer }\end{array}$ & $\begin{array}{l}\text { Divalent } \\
\text { metals; } \\
\text { mostly Fe, } \\
\text { but also } \mathrm{Ni} \\
\text { (see both } \\
\text { Figure } 2 \\
\text { and Table } \\
\mathrm{S} 1 \text { in } \\
{[39,40] \text { ) }}\end{array}$ & $\begin{array}{c}\text { Roseovarius } \\
\text { nubinhibens } \\
13.8+/-5.5 \\
\mathrm{mM}[34]\end{array}$ & $\begin{array}{l}\text { Mostly in "Roseobacters" } \\
\text { Sporadically in } \text { - }^{-} \\
\text {Proteobacteria (e.g. } \\
\text { Vibrio, Pseudomonas, } \\
\text { Oceanimonas. Notably, } \\
\text { functional DddP enzyme } \\
\text { found in Ascomyctete } \\
\text { fungi - including } \\
\text { Aspergillus and Fusarium }\end{array}$ \\
\hline DddL "lyase" & acrylate + DMS + proton & Cupin & No & $\begin{array}{c}\sim 230 \text { amino acids; } \\
\text { MW } \sim 26 \mathrm{kDa}\end{array}$ & Not Tested & Not tested & $\begin{array}{c}\text { Rhodobacterales - mainly } \\
\text { in Roseobacters }\end{array}$ \\
\hline $\begin{array}{l}\text { DddQ } \\
\text { "lyase" }\end{array}$ & acrylate + DMS + proton & Cupin & $\begin{array}{c}\text { Yes, from } \\
\text { Ruegeria } \\
\text { lacuscaerulensis } \\
{[42]}\end{array}$ & $\begin{array}{l}\text { 200 amino acids; } \\
\text { MW } 22 \text { kDa dimer }\end{array}$ & $\mathrm{Zn}$ & $\begin{array}{c}\text { Ruegeria } \\
\text { lacuscaerulensi } \\
\text { s } 21.5+/-6.8 \\
\mathrm{mM}[42] \\
\end{array}$ & Roseobacters \\
\hline $\begin{array}{l}\text { DddW } \\
\text { "lyase" }\end{array}$ & acrylate + DMS + proton & Cupin & $\begin{array}{l}\text { No, but see [43] } \\
\text { for in vitro } \\
\text { analyses for } \\
\text { Ruegeria } \\
\text { pomeroyi }\end{array}$ & $\begin{array}{l}\text { 150 amino acids; } \\
\text { MW } 16 \text { kDa }\end{array}$ & $\mathrm{Fe}(\mathrm{II})$ & $\begin{array}{c}\text { Ruegeria } \\
\text { pomeroyi } \\
8.7+/-0.7 \mathrm{mM} \\
{[43]}\end{array}$ & $\begin{array}{c}\text { A few Roseobacters and } \\
\text { other Rhodobacterales } \\
\text { e.g. Ponticoccus }\end{array}$ \\
\hline
\end{tabular}


Figure 1.

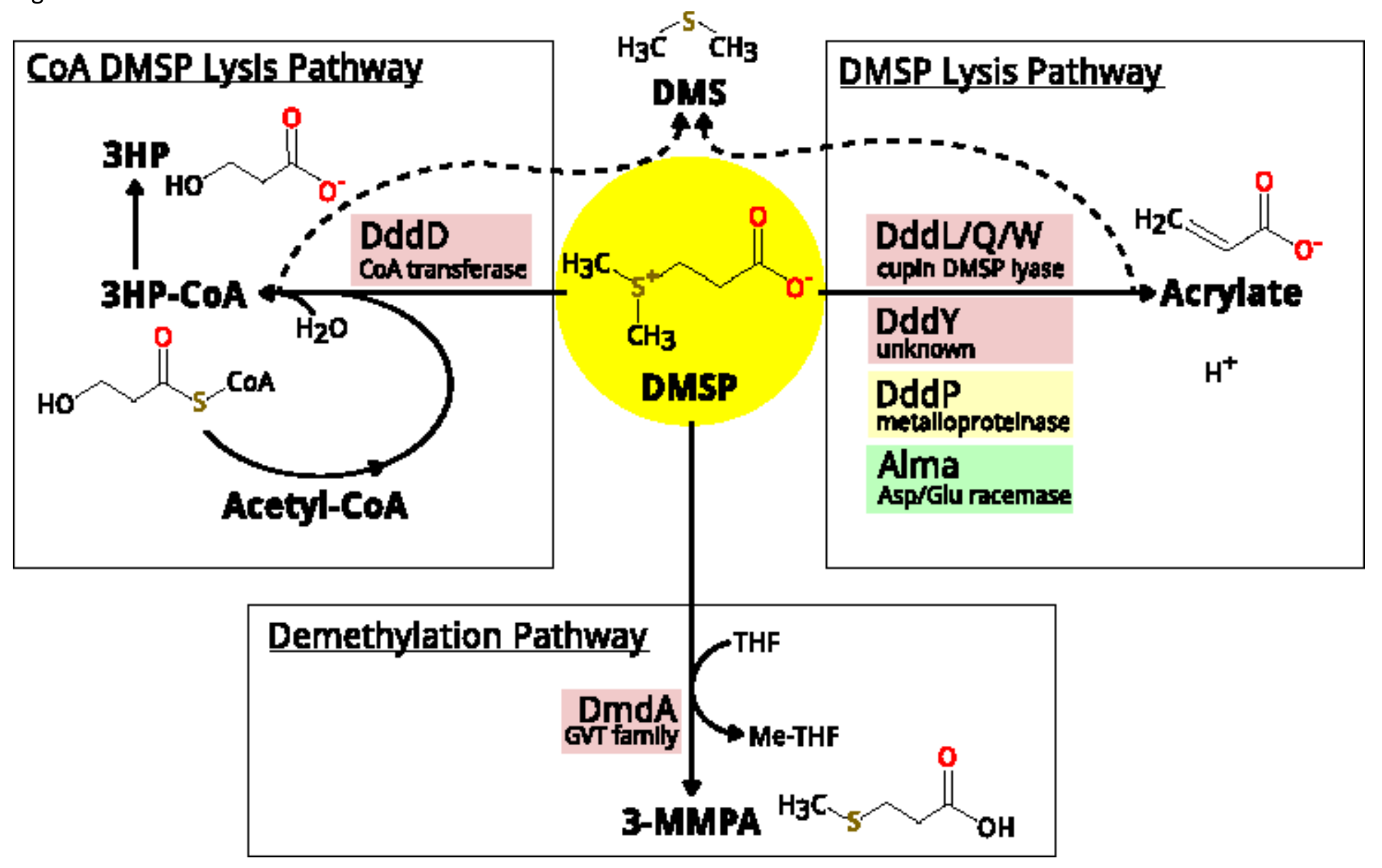


Figure 2a.

Cupin Motif 1

Cupin Motif 2

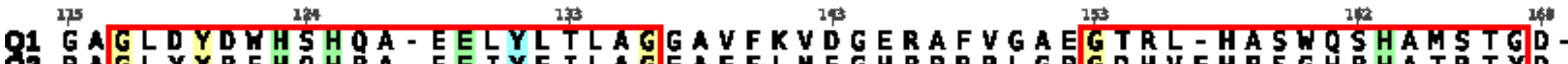

92 PAGLYYPFHQHPA- EE IYF ILAGEAEFLMEGHPPRRLGPGDHVFHPSGHPHATRTYD-

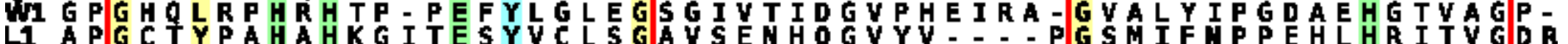

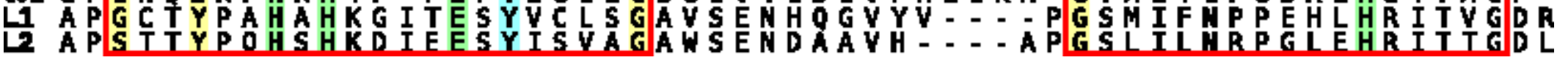




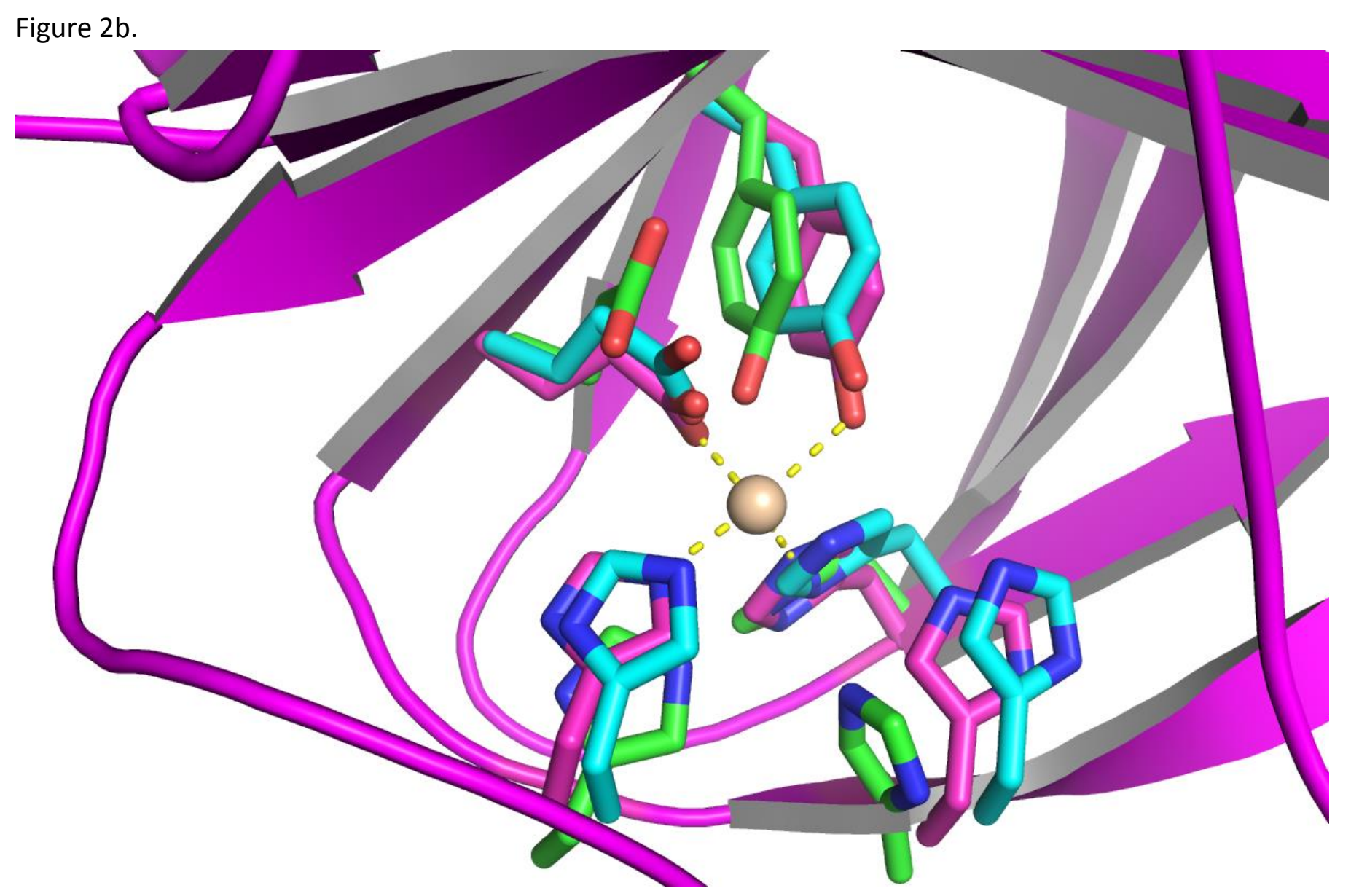

